\title{
Patient perceptions on telemedicine eye clinics during COVID-19 pandemic
}

\author{
Ahmad Sharara ${ }^{1}$, Vinaya Felcida ${ }^{1}$, Saba Anwar ${ }^{1}$, Shalika Perera ${ }^{1}$, and Peck Lin Lip ${ }^{1}$ \\ ${ }^{1}$ Birmingham and Midland Eye Centre
}

February 5, 2021

\section{Hosted file}

Letter Survey results.pdf available at https://authorea.com/users/393794/articles/507359patient-perceptions-on-telemedicine-eye-clinics-during-covid-19-pandemic

\section{Hosted file}

Table 1 Survey results.pdf available at https://authorea.com/users/393794/articles/507359patient-perceptions-on-telemedicine-eye-clinics-during-covid-19-pandemic 